\title{
Academic Dishonesty in the Philippines: The Case of 21st Century Learners and Teachers
}

\section{Mark Gabriel Wagan Aguilar}

School Director, ABE International Business College-Fairview, Quezon City, Philippines OrcidID: 0000-0003-0077-3567; E-mail: markgabrielaguilar@gmail.com

Area/Section: Education Management.

Type of the Paper: Exploratory Research.

Type of Review: Peer Reviewed as per $|\mathrm{C}| \mathrm{O}|\mathrm{P}| \mathrm{E} \mid$ guidance.

Indexed in: OpenAIRE.

DOI: https://doi.org/10.5281/Zenodo.5091613

Google Scholar Citation: IJMTS

\section{How to Cite this Paper:}

Mark Gabriel Wagan Aguilar, (2021). Academic Dishonesty in the Philippines: The Case of 21 st Century Learners and Teachers. International Journal of Management, Technology, and Social Sciences (IJMTS), 6(1), 306-313. DOI: https://doi.org/10.5281/Zenodo.5091613.

International Journal of Management, Technology, and Social Sciences (IJMTS) A Refereed International Journal of Srinivas University, India.

CrossRef DOI: https://doi.org/10.47992/IJMTS.2581.6012.0146

(C) With Author.

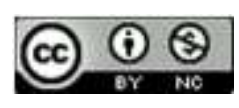

This work is licensed under a Creative Commons Attribution-Non-Commercial 4.0 International License subject to proper citation to the publication source of the work.

Disclaimer: The scholarly papers as reviewed and published by the Srinivas Publications (S.P.), India are the views and opinions of their respective authors and are not the views or opinions of the SP. The SP disclaims of any harm or loss caused due to the published content to any party. 


\title{
Academic Dishonesty in the Philippines: The Case of 21st Century Learners and Teachers
}

\author{
Mark Gabriel Wagan Aguilar \\ School Director, ABE International Business College-Fairview, Quezon City, Philippines \\ OrcidID: 0000-0003-0077-3567; E-mail: markgabrielaguilar@gmail.com
}

\begin{abstract}
Purpose: Studies revealed that in the eyes of teachers, online education leads to more academic dishonesty, however, this study does not intend to justify that it is more prevalent in this mode of learning compared with physical classes. Nevertheless, the world has shifted to a modern learning approach called online education when the pandemic brought significant changes in people's lives, and that the respondents of this study were students who during the data gathering procedure are enrolled in courses that utilize online learning approach and "academic servers" who during the same process are offering their services to students enrolled in the same mode of learning. This has led to this study that primarily aims to explore the industry of academic servicing that is believed to be a platform where academic dishonesty is tolerated and widely practiced amidst the new normal.
\end{abstract}

Design/Methodology/Approach: This study has focused on 650 members of three groups in social media that promotes academic servicing where students can transact with people who offers their services in doing students' academic requirements. The researcher utilized a qualitative-descriptive research approach whereas Semi-Structured interviews have been conducted and coding has been performed to analyze the data collected.

Findings/Result: Results show that there is lack of discipline among students of the 21st century, particularly students who have enrolled during academic year 2020-2021, whereas, it is in the Senior High School Level and College Level where academic dishonesty is most prevalent. It was revealed that the key players in this "industry" aside from these students includes private and public-school teachers, unemployed senior high school and college graduates, and industry professionals. Most people who offer their services to do students' academic requirements who are called academic servers are teachers, and they usually earn between Php. 1,500.00 and Php. 20,000.00 on a weekly basis from their clients who pay an average of Php. 500.00 per work. The top reasons why students engage in academic dishonesty are the overwhelming workload which is linked to poor time management, inability to independently study which is linked to poor or zero understanding on lessons and low support from teachers and parents, laziness, influence of peers, and pressure to get good grades, while the main motivation of academic servers in offering their services to students is to earn money, though some have expressed that at the same time, they would like to help struggling students. Results of this study shows low quality of education in the country and poor integrity of graduates of school year 2020-2021, and indicates clear violation of the code of ethics for professional teachers.

Originality/Value: This study explored a problem in education that has been poorly addressed in the Philippines over the years. This study shows low quality of education in the country and poor integrity of graduates of school year 2020-2021, and indicates clear violation of the code of ethics for professional teachers. Results also questions the effectiveness of online learning in the Philippines, which the researcher believes to be relevant today as educational institutions shifted to online classes.

Paper Type: Exploratory Research

Keywords: Academic Dishonesty, Education, Teachers, Academic Servicing, Ethics

1. INTRODUCTION : 
The world has shifted to a modern learning approach called online education as soon as the pandemic brought significant changes in people's lives, including on how they do their academic requirements. This has led to this study that aims to discover a practice that has been assumed by many to be observed during the new normal - academic dishonesty. Online learning has been known to be a form of distance education that utilizes technological advances such as computers, cellphone, and other electronic gadgets alongside with Internet with at least $80 \%$ of all the lessons being taught online (Allen \& Seaman, 2008 [1]). Studies suggest that online education began in 1981 when the first fully online course was offered by the Western Behavior Sciences Institute, and when colleges and universities followed by offering online classes beginning in the mid-1980's. In today's generation, it was very obvious that most people are already aware towards online learning because of the emergence of technology, in fact, in the study conducted by Yacob et al (2012) [2]; it has been proven that the level of awareness towards elearning among students is high and it even increased more when COVID19 affected schooling due to interventions the educational institutions in cooperation with the government have to make (Nafrees et al, 2020 [3]).

E-learning education system according to Mobo \& Sabado (2019) [4] promotes efficiency and leads to learners' effectiveness in learning, however, still needs improvement, while Joaquin et al (2020) [5] argue that its effectiveness would depend on the capacity of teachers, the state of the learning environment, connectivity issues, cost of materials, ability of learners, and the availability of ways to deliver classes. Sun \& Chen (2016) [5] further argue that effective online instruction depends on a course content that well-designed appropriate to the learners and teachers, positive relationship between students and teachers, trained and knowledgeable teachers, supportive online learning community, and the fast development of technology. The study added that effective strategies that can enhance universities and faculty success in transitioning to teach online are also determinants.

As we all know, there are a variety of online learning platforms that educational institutions can employ to meet their online learning requirements; the most prominent of which are Google Classroom, Zoom, and Moodle. Numerous studies have asserted its efficacy; yet, if it permits academic dishonesty, can this mode of education still be deemed effective?

Teachers' perspectives on online learning including the use of these digital sites include that it results in increased academic dishonesty, impersonality, and lack of feeling in comparison to traditional classes, as well as difficulties associated with technological utilization (Moralista \& Educado, 2020) [7]. On the other hand, Chua et al. (2020) [8] demonstrated that, despite the platform's limitations, teachers had positive interactions delivering online learning via virtual classes as an instant response to the Philippines' circumstances during the pandemic. Meanwhile, Baticulon et al. (2020) [9] emphasize that the proportion of students are not physiologically and psychologically capable of participating in online learning. The study asserts that hurdles to online learning fall into five categories: technological, individual, household, institutional, and community. All of these factors contribute to students' inability to adjust to diverse learning methods, the burden of household chores, and a lack of communication among them and their instructors.

By examining the findings of Moralista \& Educado's (2020) [7] study, which imply that this new form of learning will lead to an increase in academic misconduct, this study seeks to determine whether this is indeed the case. This study will go deeper into its prevalence, procedures, and causes. This study aims to ascertain the industry's size in terms of profitability and occurrence; who the industry's key participants are; why learners and "academic servers" participate in such behavior; and how a negotiation among prominent stakeholders starts and ends.

\section{RELATED WORKS :}

Academic dishonesty is becoming a rising awareness amongst youths in schools worldwide (Koss, 2011 [10]). Per the study, it has been a concern beginning in elementary school and continuing all the way through doctoral programs. It has been discovered that several factors contributing to its increase include expectations from instructors, families, and colleagues, the school setting, a self-centered culture, and rapidly changing media. According to Peterson (2019) [11], there is minimal evidence that cheating or academic misconduct is more widespread in online courses; however, many believe that this method of learning promotes cheating, preventing it from being widely accepted. The author claims that simply believing that online education lacks the same academic rigor as traditional methods might result in a lower level of acceptance for online degrees or certificates, not just among learners but also among 
employers. Additionally, the same survey indicated that while some argue that cheating is unavoidable and that people should simply accept it, it was emphasized that there are numerous reasons why this is not a realistic practice. As educators, it is our essential in preparing students who are both knowledgeable and ethical in their fields.

Bachore (2016) [12] asserts that academic dishonesty/cheating is widespread, particularly with regard to examination-related cheating and plagiarism on written assignments and papers. According to the findings, the practices were motivated by the difficulty of exams, a lack of time, the irrelevance of course material, the pressure to earn good grades and a loss of clarity about the policy, and the need for extra points to raise their grades, all of which were high commonly confirmed reasons. Additionally, the survey established that the top three unethical activities noticed are submitting an assignment that was not produced by the student, duplicating content from a source material without giving credit, and copying from another student during a test. Meanwhile, according to Anitha \& Sundaram (2021) [13], a number of learners acknowledged to cheating at least once on their academic requirements in a college in Andhra Pradesh, India; 93.4 percent of students admitting to academic cheating. The study discovered that seeking assistance from public knowledge, plagiarism, lying, and exam cheating are the most prevalent behaviors correlated with student deception, while parental influence, conformity, enrolling in courses due to external influences such as parental choice or social pressures, high competition for grades, and reservations about education are the most significant repercussions.

According to a study conducted by Bayaa Martin Saana et al. (2016) [14], approximately 92 percent of the students in an African institution were aware of the institution's policies regarding academic dishonesty; however, approximately $40 \%$ of students had witnessed their peers cheating and approximately 94 percent had never reported these acts, implying that they were tolerating the bad practice and disobeying the police. The quest of high marks, a heavy academic load, and the need to impress family and guardians were the primary factors that contributed to the harmful habit. According to the study's findings, the most prevalent form of academic dishonesty was dishonesty during assessments and inappropriately exchanging answers during the completion of assignments. Nonetheless, these students concluded that while copying peers' work without permission was a significant infraction, duplicating it with consent was not.

\section{OBJECTIVES :}

The study primarily aims to explore the industry of academic servicing that is believed to be a platform where academic dishonesty is tolerated and widely practiced. This study will further investigate its prevalence, processes, and reasons behind. This particularly seeks to determine how big is the industry in terms of revenue and prevalence; who are the key players; what are the reasons why students and "academic servers" engage on such type of practice; and how does a transaction between key players begins and ends.

\section{METHODOLOGY :}

This study utilized a qualitative-descriptive research approach. The data gathering procedure involved review of literatures published in journals and other academic resources and semi-structured interviews with 300 students who pay people to do their academic requirements, and 350 "academic servers", who all have been selected randomly through three groups in social media that promotes academic servicing where students can transact with people who offers their services in doing students' academic requirements. The researcher decided for this number since there is no existing data regarding how many are involved in this kind of business, moreover, the number of academic servers is higher since along the process of gathering data, the researcher has found out that there are students who pay other people to do their academic requirements, who at the same time offer their services to other students for papers that they capable of doing, unlike most academic servers who are just offering their services and not seeking the services of others, hence, giving an impression that there are more academic servers than students who just need the services of others in doing their academic requirements.

Semi-Structured interviews have been conducted with the 650 respondents. According to DeJonckheere \& Vaughn (2019) [15], this kind interview format consists of a conversation between the researcher and the participant, guided by a flexible interview protocol and supplemented by follow-up questions, 
probes, and comments, which allows the researcher to collect open-ended data, to explore participant thoughts, and be able to collect more important data as possible. This type of interview is commonly used in qualitative research, making it suitable for this study. Coding of data was performed and information provided have been analyzed, leading to conclusions about the revenue and prevalence of this business in terms of scope of work, place, degree level, experience level of key players; who are the key players in this "industry"; what are the reasons why learners pay someone to do their work; what are the reasons why academic servers entered this kind of job; and how does a transaction between key players begins and ends.

\section{RESULTS AND DISCUSSIONS :}

\subsection{Revenue, Prevalence, and Key players:}

Among the 350 academic servers, 213 earns an average of Php. 1,761.00 on a weekly basis, while 84 earns an average of Php. 7,645.00, and 53 earns an average of 13,632.00, whereas, majority are earning between Php. 5,000 and Php. 8,000 on a monthly basis. Through the interviews, it has been determined that most academic servers are senior high school students (31\%) who at the same time seek services from others for their academic requirements, followed by college students (28\%), who do the same, then teachers (25\%) who only offer their services and do not seek the services of others, then unemployed senior high school and college graduates (12\%), and industry professionals (4\%). While most students who seek the services of academic servers are in the college level at $45 \%$, while only $30 \%$ are in the senior high school level, $23 \%$ are currently pursuing master's degree, and $2 \%$ are enrolled in the doctorate degree level.

Among the teachers involved, there are $49(56 \%)$ who are licensed professional teachers, $36(41 \%)$ who are pursuing Master's degree, $14(16 \%)$ who are pursuing Doctorate degree, $39(45 \%)$ who are teaching in private schools, and 48 (55\%) who are teaching in public schools. Focusing on the perception of students and teachers given that they have recorded the highest involvement, it has been determined that $100 \%$ of teachers are aware that what they are doing is an act of academic dishonesty, while among senior high school and college students, all of them thinks the same, which explains why many use fake accounts in social media when transacting, however, $76 \%$ of the students believes that this practice is reasonable due to the challenges they face in studying, particularly in the new normal.

\subsection{Reasons why students ask others to do their academic requirements:}

Table 1: Keywords found in the responses of students

\begin{tabular}{|l|l|}
\hline Themes & Keywords found in the responses of students \\
\hline Overwhelming Workload & $\begin{array}{l}\text { "several things to do", "too much work needed to be } \\
\text { submitted", "many requirements", "cannot meet deadlines", } \\
\text { "hectic schedules", "many demands from teachers" }\end{array}$ \\
\hline $\begin{array}{l}\text { Poor Independent Learning } \\
\text { Capability }\end{array}$ & $\begin{array}{l}\text { "I don't understand lessons", "I don't know what needs to be } \\
\text { done", "I cannot understand the topics", "I did not learn from } \\
\text { class", "I am not intelligent" }\end{array}$ \\
\hline $\begin{array}{l}\text { Low support from teachers and } \\
\text { parents }\end{array}$ & $\begin{array}{l}\text { "nobody is teaching me", "my teachers are irresponsive to my } \\
\text { questions", "my parents do not understand my lessons", "my } \\
\text { parents do not want to teach me", "I cannot understand what the } \\
\text { teachers are explaining during class" }\end{array}$ \\
\hline Laziness & $\begin{array}{l}\text { "I am feeling lazy", "I am engaged with activities with friends", } \\
\text { "I am busy with social media", "I find studying boring", "I am } \\
\text { not interested to study lessons", "I know someone else will do } \\
\text { it" }\end{array}$ \\
\hline Influence of peers & $\begin{array}{l}\text { "My friends/classmates told me about academic servicing", } \\
\text { "My friends/classmates push me to just pay for someone to do } \\
\text { my academic requirements instead of having a difficult time" }\end{array}$ \\
\hline Pressure to get good grades & $\begin{array}{l}\text { "I want to have good grades", "I want to maintain my good } \\
\text { grades", "competition is tight in our class", "my parents always } \\
\text { remind me that I need to have good grades", "I need to pass the } \\
\text { subject/course", "I must not fail" }\end{array}$ \\
\hline
\end{tabular}




\subsection{Reasons why students, teachers, and other so called "academic servers" offer their services to students for their academic requirements:}

Table 2: Keywords found in the responses of academic servers

\begin{tabular}{|l|l|}
\hline Themes & Keywords found in the responses of academic servers \\
\hline Opportunity to earn money & $\begin{array}{l}\text { "to earn money", "additional income", "high pay", "to save } \\
\text { money", "for business" }\end{array}$ \\
\hline Help struggling students & $\begin{array}{l}\text { "to give a hand to students who are having a hard time", "to } \\
\text { give assistance to students who has low IQ", "to give } \\
\text { assistance to students who have no time to do their } \\
\text { requirements due to being working students" }\end{array}$ \\
\hline
\end{tabular}

5.5 How do transactions take place?

Most of the respondents (71\%) said that transactions begin with academic servers promoting themselves through posts, whereas, once read by a student who is searching for someone who could do his/her academic requirement, will send the academic server a message to inquire, while $29 \%$ believes that it starts from posts of students about their need of an academic server who could do their requirements, whereas, once read by an academic server, will either leave a comment or send the student a message. From there, the task will be discussed, deadline will be set, and the cost will be negotiated. Majority of the respondents (78\%) also said that there are times when a client asks academic servers for IDs and proof of successful transactions, which is usual if an academic server uses a fake account. Meanwhile, for the security of academic servers, most academic servers (91\%) require clients to make $50 \%$ down payment, while $6 \%$ only accepts work from clients who have paid $100 \%$ upfront, and only $3 \%$ accepts work without the client making any payment. However, most of the latter gets scammed; hence, fails to get the payment after working on the task.

\section{CONCLUSION :}

Through the findings, the researcher hereby concludes that there is lack of discipline among students of the 21st century, particularly students who have enrolled during academic year 2020-2021, whereas, it is in the Senior High School Level and College Level where academic dishonesty is most prevalent. This also indicates that senior high school and college students are more likely to finish the academic year 2020-2021 without learning and not deserving the marks that they have received. It is also concluded that aside from the reasons stated by the students on why they engage in academic dishonesty, it is the teachers who encourage them to cheat as this study have found out that teachers including licensed ones tolerate academic dishonesty by offering themselves to do the academic requirements of students. It is assumed that by seeing teachers involved in this kind of business, students gain a higher level of confidence.

Though there are numerous reasons why key players engage in this kind of practice, it has been found out that the overwhelming workload, inability to independently study, low support from teachers and parents, laziness, influence of peers, and pressure to get good grades are the main reasons why students seek the services of others in doing their requirements, thus, leading to a conclusion that online learning has not been effective. While academic servers reasons in offering their services to students is to earn money and their desire to help struggling students, which indicates that the salary they receive is insufficient. Furthermore, the results also indicate clear violation of the code of ethics for professional teachers in the Philippines despite being aware of its provisions, particularly the mandate to uphold the highest possible standards of quality education and teachers' obligation to maintain at all times a dignified personality which could serve as a model worthy of emulation by learners, peers and all others. This indicates that many teachers in today's generation may not be totally aware of their roles, does not believe in what the policy says, or simply has a mindset that the policy is weak, thus, violating it won't do any harm. The result of this study clearly lowers the quality of education in the country, negatively affects the image of graduates, and establishes poor integrity of the teaching profession.

\section{RECOMMENDATIONS :}

Inspired by the results of this study, the following recommendations are hereby presented. 
- Increase teachers' salary

- Strengthen the policies appertaining to academic dishonesty and ethics of professional teachers through monitoring and regular evaluations.

- Provide a flexible and more accessible learning methodology depending on the capability of students.

- Regularly conduct seminars towards academic dishonesty and ethics for students and teachers.

- Introduce a course/subject that would focus on discipline, honesty, integrity, and other positive values in the senior high school and college levels.

- Require oral assessments aside from written works, especially if the mode of learning is online or modular.

- Regularly organize sessions with parents where challenges faced by students will be discussed and the need to provide support for them.

\section{REFERENCES :}

[1] Allen, I., \& Seaman, J. (2008): Staying the course: Online education in the United States. The Online Learning Consortium. Available at https://eric.ed.gov/?id=ED529698

[2] Yacob, A., Kadir, A., Zainudin, O., \& Zurairah, A. (2012): Student Awareness towards E-Learning in Education. Procedia - Social and Behavioral Sciences, 67(1), 93-101.

[3] Nafrees, A., Roshan, A., Baanu, A., Nihma, M., \& Shibly, F. (2020): Awareness of Online Learning of Undergraduates during COVID 19 with special reference to South Eastern University of Sri Lanka. Journal of Physics: Conference Series, 1712. Available at https://iopscience.iop.org/article/10.1088/1742-6596/1712/1/012010

[4] Mobo F., Sabado G. (2019): An Assessment of the Effectiveness of E-Learning in AMA Olongapo Campus. Orienal Journal of Computer Science and Technology, 12(3), 99-105.

[5] Joaquin, J., Biana, H., \& Dacela, M. (2020): The Philippine Higher Education Sector in the Time of COVID-19. Frontiers in Education, 5. 576371. Available at https://www.frontiersin.org/articles/10.3389/feduc.2020.576371/full

[6] Sun, A., \& Chen, X. (2016): Online education and its effective practice: A research review. Journal of Information Technology Education: Research, 15(1), 157-190.

[7] Moralista, R. \& Educado, R. (2020): Faculty Perception toward Online Education in a State College in the Philippines during the Coronavirus Disease 19 (COVID-19) Pandemic. Universal Journal of Educational Research, 8(10), 4736-4742.

[8] Chua, E., Sibbaluca, B., Miranda, R., Palmario, G., Moreno, R., \& Solon, J. (2020): The Status of the Implantation of the E- Learning Classroom in selected Higher Education Institutions in Region IV-A amidst the COVID-19 Crisis. Journal of Critical Reviews, 7(11), 253-258.

[9] Baticulon, R., Sy, J., Alberto, N. et al. (2021): Barriers to Online Learning in the Time of COVID19: A National Survey of Medical Students in the Philippines. Medical Science Educator, 31(1), 615-626.

[10] Koss, J. (2011): Academic Dishonesty among Adolescents. University of Wisconsin-Stout, The Graduate School. Available at http://www2.uwstout.edu/content/lib/thesis/2011/2011kossj.pdf

[11] Peterson, J. (2019): An Analysis of Academic Dishonesty in Online Classes. Mid-Western Educational Researcher, 31(1), 24-36.

[12] Bachore, M. (2016): The Nature, Causes and Practices of Academic Dishonesty/Cheating in Higher Education: The Case of Hawassa University. Journal of Education and Practice, 7(19), 14-20.

[13] Anitha, P., \& Sundaram, S. (2021): Prevalence, Types and Reasons for Academic Dishonesty among College Students. Journal of Studies in Social Sciences and Humanities, 7(1), 1-14.

[14] Bayaa Martin Saana, S., Ablordeppey, E., Mensah, N., et al. (2016): Academic dishonesty in higher education: students' perceptions and involvement in an African institution. BMC Res Notes, 9, 234. Available at https://bmcresnotes.biomedcentral.com/articles/10.1186/s13104-016-2044-0\#citeas 
[15] DeJonckheere, M., \& Vaughn, L. M. (2019). Semistructured interviewing in primary care research: a balance of relationship and rigour. Family Medicine and Community Health, 7(2), 1-8. 